ARTICLE

Received 18 Dec 2015 | Accepted 12 May 2016 | Published 17 Jun 2016

DOl: $10.1038 /$ ncomms11918

OPEN

\title{
Operando NMR spectroscopic analysis of proton transfer in heterogeneous photocatalytic reactions
}

\author{
Xue Lu Wang ${ }^{1, \star}$, Wenqing Liu ${ }^{2, \star}$, Yan-Yan Yu ${ }^{3}$, Yanhong Song ${ }^{2}$, Wen Qi Fang ${ }^{1}$, Daxiu Wei ${ }^{2}$, Xue-Qing Gong ${ }^{3}$, \\ Ye-Feng $\mathrm{Yao}^{2,4}$ \& Hua Gui Yang ${ }^{1}$
}

Proton transfer (PT) processes in solid-liquid phases play central roles throughout chemistry, biology and materials science. Identification of PT routes deep into the realistic catalytic process is experimentally challenging, thus leaving a gap in our understanding. Here we demonstrate an approach using operando nuclear magnetic resonance (NMR) spectroscopy that allows to quantitatively describe the complex species dynamics of generated $\mathrm{H}_{2} / \mathrm{HD}$ gases and liquid intermediates in pmol resolution during photocatalytic hydrogen evolution reaction (HER). In this system, the effective protons for $\mathrm{HER}$ are mainly from $\mathrm{H}_{2} \mathrm{O}$, and $\mathrm{CH}_{3} \mathrm{OH}$ evidently serves as an outstanding sacrificial agent reacting with holes, further supported by our density functional theory calculations. This results rule out controversy about the complicated proton sources for HER. The operando NMR method provides a direct molecular-level insight with the methodology offering exciting possibilities for the quantitative studies of mechanisms of proton-involved catalytic reactions in solid-liquid phases.

\footnotetext{
${ }^{1}$ Key Laboratory for Ultrafine Materials of Ministry of Education, School of Materials Science and Engineering, East China University of Science and Technology, Shanghai 200237, China. ${ }^{2}$ Department of Physics, Shanghai Key Laboratory of Magnetic Resonance, East China Normal University, Shanghai 200062, China. ${ }^{3}$ Key Laboratory for Advanced Materials, Centre for Computational Chemistry, Research Institute of Industrial Catalysis, East China University of Science and Technology, Shanghai 200237, China. ${ }^{4}$ NYU-ECNU Institute of Physics at NYU Shanghai, 3663 Zhongshan Road North, Shanghai 200062, China. ${ }^{*}$ These authors contributed equally to this work. Correspondence and requests for materials should be addressed to X.-Q.G. (email: xgong@ecust.edu.cn) or to Y.-F.Y. (email: yfyao@phy.ecnu.edu.cn) or to H.G.Y. (email: hgyang@ecust.edu.cn).
} 
P roton transfer $(\mathrm{PT})$ processes in solid-liquid phases are critically important and can be encountered throughout chemistry, biology and materials science ${ }^{1-8}$. The routes and dynamics of PT processes dictate the efficiency of the key biosynthetic and energy conversion systems, both natural and artificial $^{1-4}$. Hence, tracking the PT trajectories deep into the realistic reaction becomes particularly significant. Molecular hydrogen $\left(\mathrm{H}_{2}\right)$ is a clean-burning fuel that can be produced from protons in the reductive half reaction of solar water splitting where the proton-related species are involved ${ }^{2,9}$. Nevertheless, critically important problems including side reactions restrict the productivity of the photocatalytic hydrogen evolution reaction (HER), in which the catalytic steps involve the coupling of lightgenerated redox equivalents to PT. In these cases, PT in HER is multidirectional. Thus, the addition of specific molecular reagents (also called sacrificial reagents), which is thermodynamically more oxidizable than water $\left(\mathrm{H}_{2} \mathrm{O}\right)$, into the reaction environment can suppress the recombination of photogenerated charge carriers and the corresponding reverse reactions to some extent ${ }^{10}$. However, from a fundamental standpoint, some molecular reagents themselves contain protons, such as methanol, ethanol and triethanolamine, which means that such molecular agent itself can be a proton source and this undoubtedly increases the complexity of HER. Therefore, the vague and ambiguous proton source, PT routes, as well as the reaction mechanisms greatly limit our understanding and in turn the development of this field.

Recently, a series of methodologies for mechanism study, such as scanning tunnelling microscopy ${ }^{11-13}$, time-resolved twophoton photoemission ${ }^{14}$, temperature-programmed desorption ${ }^{15-17}$, infrared spectroscopy ${ }^{18-20}$, solid-state nuclear magnetic resonance $21-24$ and density functional theory calculations $(\mathrm{DFT})^{25,26}$ have been used to address the central questions in HER. These methods can simulate and observe a rich surface chemistry of the interaction between adsorbed molecules and catalyst substrates, and distinguish various possible HER mechanisms. However, few of these techniques alone permit the direct quantification of specific species in reactions, and, moreover, the vast majority of them usually operate under ideal conditions (solid-gas or in ultrahigh vacuum), albeit with exquisite resolution, and it is still a quite tough task to take into account the complexities of practical conditions such as solvent effect, surface specificity and adsorbate-adsorbate interactions. For instance, the adsorption and dissociation of methanol $\left(\mathrm{CH}_{3} \mathrm{OH}\right)$ gas can occur easily on anatase- $\mathrm{TiO}_{2}$ (101) surface under continuous ultraviolet illumination; however, in the liquid solution weak interactions such as hydrogen-bonding effects between $\mathrm{CH}_{3} \mathrm{OH}$ and $\mathrm{H}_{2} \mathrm{O}$ may significantly complicate the reaction and probably impair the conclusion/mechanism derived from the ideal reaction conditions. Furthermore, some possible hydrolysates in HER are out of ability to be observed under the gas-solid vacuum condition, and some changes that occur during the reaction may no longer be apparent when the sample returns to a non-working state. In this regard, there still exists a large gap between over-idealized conclusions and realistic heterogeneous reaction systems. Yet, to the best of our knowledge, no experimental evidence for quantitative insight into the PT mechanisms of HER in solid-liquid phases has been reported.

Here we demonstrate an approach, using operando NMR spectroscopy, that allows to directly quantify the populations of $\mathrm{H}_{2} / \mathrm{HD}$ gases and liquid intermediates in pmol resolution, as well as the tracking of the PT routes deep into the realistic heterogeneous HER conditions, which contains $\mathrm{Pd} / \mathrm{TiO}_{2}$ (anatase), $\mathrm{H}_{2} \mathrm{O}$ and $\mathrm{CH}_{3} \mathrm{OH}$. In this system, the effective protons for HER are mainly from $\mathrm{H}_{2} \mathrm{O}$, and $\mathrm{CH}_{3} \mathrm{OH}$ evidently serves as an outstanding sacrificial agent reacting with holes. Furthermore, it also provides evidence to rule out controversy about the complicated sources of protons for HER and the role of methanol as sacrificial molecules, with the methodology offering possibilities for the quantitative mechanism studies of proton-related catalytic reactions.

\section{Results}

Experimental set-up of operando NMR. Our experimental set-up consists of a micro-reactor system based on a NMR tube, allowing solid-liquid heterogeneous mixture to be directly studied inside the NMR coil. The experimental scheme is illustrated in Fig. 1 and Supplementary Fig. 1. The light source ( $300 \mathrm{~W}$ Xe lamp) beam is directed through a focusing lens assembly to converge on the entrance face of a homemade optical fibre bundle (seven quartz fibres, diameter $3 \mathrm{~mm}$ ). The NMR study is incident on a suspension containing solid photocatalyst together with the aqueous mixtures, and the signals originate from not only the solid photocatalyst itself but also from the different gas-liquid molecules and chemical species dissolved in the solution ${ }^{27,28}$. This designed scheme has provided excellent feature information among the solid, liquid and gas mixtures without the separation of products. Our NMR studies are carried out on $700-\mathrm{MHz}$ Agilent NMR spectrometers at a magnetic field strength of $16.4 \mathrm{~T}$. An Agilent $5 \mathrm{~mm} \mathrm{z}$-axis pulsed field gradient triple resonance probe $\left({ }^{1} \mathrm{H}\left\{{ }^{13} \mathrm{C},{ }^{15} \mathrm{~N}\right\}\right)$ is used (Detailed information can be found in Supplementary Fig. 2 and Supplementary Note 1).

To operando probe molecular species qualitatively and quantitatively in the solid-liquid phases, we measured some benchmark experiments (Supplementary Figs 3-10). First, the ${ }^{1} \mathrm{H}$ NMR signals of aqueous suspensions containing $\mathrm{TiO}_{2}, \mathrm{CH}_{3} \mathrm{OH}$ and $\mathrm{D}_{2} \mathrm{O}$ were examined (Supplementary Figs 7 and 8). Two resonance peaks were clearly observed, corresponding to the methyl group $\left(\mathrm{CH}_{3}^{-}\right)$of $\mathrm{CH}_{3} \mathrm{OH}$ (Supplementary Fig. 8b) and the

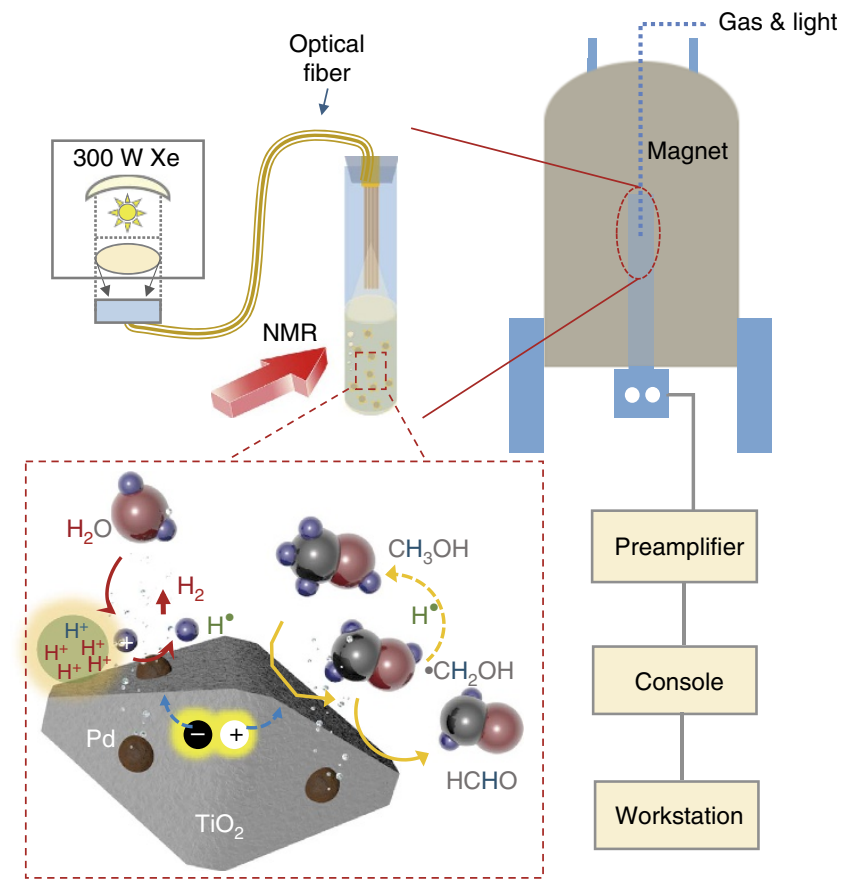

Figure 1 | Schematic layout of set-up for operando NMR studies. The set-up consists of a micro-reactor system based on a homemade NMR tube, allowing solid-liquid heterogeneous mixture to be directly studied inside the NMR coil while maintaining good uniformity. The light source (300-W Xe lamp) beam was directed through a focusing lens assembly to converge on the entrance face of a homemade optical fibre bundle (seven quartz fibres, diameter $3 \mathrm{~mm}$ ). 
residual protons of $\mathrm{D}_{2} \mathrm{O}$ (Supplementary Fig. $\left.8 \mathrm{a}\right)^{29}$. Interestingly, the signal of $\mathrm{H}_{2}$ (singlet, 4.57 p.p.m.) was also remarkably detected in the spectrum of the suspension when the $\mathrm{H}_{2}$ gas was injected into it (Supplementary Fig. 9). This could provide the way to quantitatively evaluate the amount of $\mathrm{H}_{2}$ in the aqueous solution by comparing with the signal from the solution of saturated dissolved $\mathrm{H}_{2}$. Second, the signal sensitivity was evaluated. Take 3-(trimethylsilyl)-1-propanesulfonic acid sodium salt (DSS) for example; when we decreased the content of DSS to nearly $50.7 \mathrm{pmol}$, the signal still had a relatively good signal-tonoise ratio (Supplementary Fig. 10). Even though by unitary sampling (number of scans is 1) of the heterogeneous mixture, the signals still had a good signal-to-noise ratio and thus could be distinctly distinguished. Therefore, the signals measured by the operando NMR could have pmol sensitivity, indicating a good capability to operando probe the gas-liquid intermediate products quantitatively deep into the solid-liquid working conditions at the very early stage of the reaction.

Operando NMR spectroscopy measurements. In a photocatalysis system, electrons are shuttled to the reductive side where they reduce protons to $\mathrm{H}_{2}$. However, because of the complexity in building and optimizing such a complete system, when studying the reductive half reaction, it is common for a sacrificial electron donor to be used to optimize catalysts for $\mathrm{H}_{2}$ production. Thus, for a clear recognition of the PT routes, it is significant to clarify the roles of the sacrificial agents. Widely accepted explanations of the roles for sacrificial agents (for example, methanol) are the thermodynamically more oxidizable ability than water, which work as an external driving force for the surface chemical reactions ${ }^{12}$. Their effects have been attributed to the consumption of holes, with the aim of suppressing the recombination of photogenerated charge carriers and the surface back reaction, which results in an increased $\mathrm{H}_{2}$ evolution ${ }^{30}$. Yet, no experimental evidence for this mechanism was reported. On the other hand, some groups (for example, Xu et al. ${ }^{15}$ and Highfield et al. ${ }^{19}$ ) pointed out that photo-reforming of methanol (gas) over the photocatalyst may also produce pure $\mathrm{H}_{2}$, which makes it plausible to assume that the protons from methanol sacrificial agent have participated in the HER. However, these experimental simulations under ideal conditions depend on assumptions and simplifications, and many questions concerning details of the mechanisms in real conditions without the separation of products remain unanswered. As a consequence, the vague and ambiguous roles of sacrificial agents greatly limit our understanding of the PT routes.

To clarify these issues, NMR was applied on two deliberately designed reaction systems, namely System $1\left(\mathrm{H}_{2} \mathrm{O} / \mathrm{CD}_{3} \mathrm{OD} /\right.$ catalyst) and System $2\left(\mathrm{CH}_{3} \mathrm{OH} / \mathrm{D}_{2} \mathrm{O} /\right.$ catalyst $)$, to provide some qualitative preliminary results. The virtue of those systems lays on the variation of the protonated agent of the similar reaction, which allows selective monitoring of the PT routes in HER. Figure 2a shows ${ }^{1} \mathrm{H}$ NMR spectra of these two systems before and after the irradiation with ultraviolet/visible (UV/Vis) light. No $\mathrm{H}_{2} /$ HD NMR signal is observed for these samples in the dark. Upon irradiation for $2 \mathrm{~h}$, the $\mathrm{H}_{2}$ signal (single, 4.56 p.p.m.) and the HD signal (triplet, 4.46, 4.52 and 4.57 p.p.m.) resonances are clearly observed for System 1 . Whereas only trace amount of $\mathrm{HD}$ gas (triplet, 4.47, 4.53 and 4.58 p.p.m.) is found for System 2, although this system has been irradiated for $24 \mathrm{~h}$ before the NMR study. Considering the solution compositions of System 1, we conclude that the proton source of the $\mathrm{H}_{2}$ gas in the photocatalysis system, $\mathrm{H}_{2} \mathrm{O} / \mathrm{CH}_{3} \mathrm{OH} /$ catalyst, is at least partial from $\mathrm{H}_{2} \mathrm{O}$ definitely.

For a deeper understanding, we changed the concentration of $\mathrm{H}_{2} \mathrm{O}$ of System 1. As can be seen from Fig. $2 \mathrm{~b}$ and Supplementary a
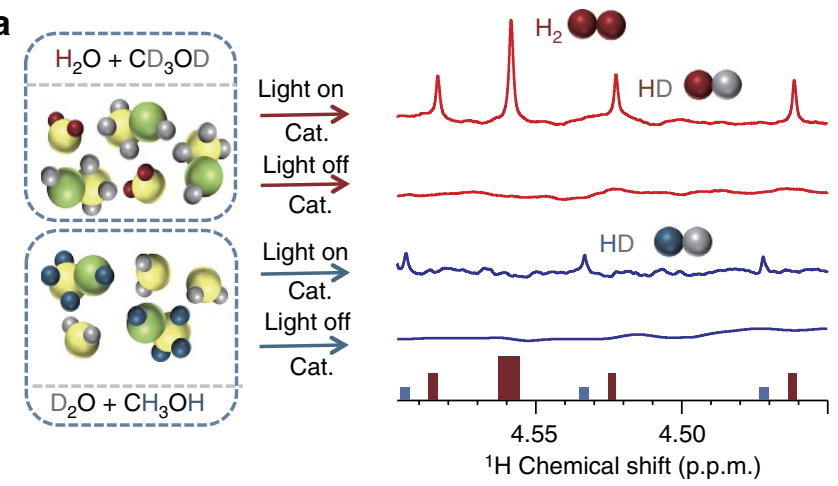

b

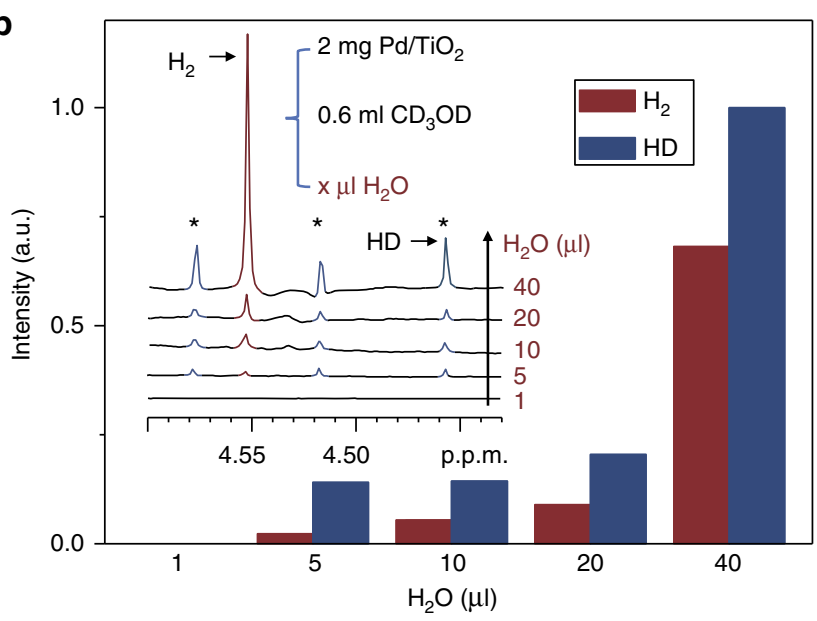

Figure $\left.2\right|^{1} \mathbf{H}$ NMR spectra of different systems. (a) ${ }^{1} \mathrm{H}$ NMR spectra of $\mathrm{H}_{2} / \mathrm{HD}$ gases produced from heterogeneous systems before and after the irradiation with UV/Vis light. The spectra were acquired from samples containing $(A, B) \mathrm{CH}_{3} \mathrm{OH}(20 \mu \mathrm{l}), \mathrm{D}_{2} \mathrm{O}(500 \mu \mathrm{l})$ and $\mathrm{Pd} / \mathrm{TiO}_{2}(2 \mathrm{mg})$ at $298 \mathrm{~K}$ with a 5 s recycle delay and 16 scans before $(A)$ and after (B) the UV/ Vis irradiation for $24 \mathrm{~h}$; $(\mathrm{C}, \mathrm{D}) \mathrm{H}_{2} \mathrm{O}(20 \mu \mathrm{l}), \mathrm{CD}_{3} \mathrm{OD}(500 \mu \mathrm{l})$ and $\mathrm{Pd} / \mathrm{TiO}_{2}(2 \mathrm{mg})$ at $298 \mathrm{~K}$ with a $5 \mathrm{~s}$ recycle delay and 32 scans before (C) and after (D) the UV/Vis irradiation (300-W Xe lamp) for $2 \mathrm{~h}$. The shifts of the $\mathrm{H}_{2} / \mathrm{HD}$ peaks are caused by the different deuterated reagents.

(b) ${ }^{1} \mathrm{H}$ NMR spectra of the correlations between produced $\mathrm{H}_{2} / \mathrm{HD}$ gas and added $\mathrm{H}_{2} \mathrm{O}$. The $\mathrm{NMR}$ experiments were acquired from samples containing $\mathrm{Pd} / \mathrm{TiO}_{2}(2 \mathrm{mg}), \mathrm{CD}_{3} \mathrm{OD}(600 \mu \mathrm{l}), \mathrm{D}_{2} \mathrm{O}(1 \% \mathrm{DSS}$ as the internal reference) and $\mathrm{H}_{2} \mathrm{O}(x \mu \mathrm{l}, x=1,5,10,20,40)$ at $298 \mathrm{~K}$ with a $5 \mathrm{~s}$ recycle delay and 32 scans after the UV/Vis irradiation for $2 \mathrm{~h}$.

Fig. 11, it is observed that the signal intensity of $\mathrm{H}_{2}$ gas in the NMR spectra increases with the content of the adding $\mathrm{H}_{2} \mathrm{O}$. This is another direct evidence for its involvement in $\mathrm{PT}$ (from $\mathrm{H}_{2} \mathrm{O}$ to $\mathrm{H}_{2}$ ), which can support our deduction for the origin of $\mathrm{H}_{2}$ in System 1 . Note that the H/D isotope effect has been realized in literature ${ }^{31,32}$. The presence of the H/D isotope effect can decrease the reaction rate of water splitting; however, in principle will not harm our deduction for the origin of $\mathrm{H}_{2}$ in the studied reaction system.

The origin of $\mathrm{HD}$ gas is an intriguing question and also related to the photocatalytic mechanism. In a mixture of $\mathrm{H}_{2} \mathrm{O}$ and $\mathrm{CD}_{3} \mathrm{OD}$, few $\mathrm{HDO}$ and $\mathrm{CD}_{3} \mathrm{OH}$ species can be generated because of the H/D exchange reactions ${ }^{33}$, which further increases the complexity of the origin of HD gas. For System 1, there are two possibilities for the origin of HD gas: the product of HDO or the reforming product of $\mathrm{CD}_{3} \mathrm{OH}$. As inspired by the work of Yang et al. ${ }^{17}$, the methyl group $\mathrm{H}$ of $\mathrm{CH}_{3} \mathrm{OH}$ would transfer to the $\mathrm{O}_{\mathrm{BBO}}$ sites of $\mathrm{TiO}_{2}$ (anatase) when it is photocatalytically dissociated, while proton reduction reaction prefers to occur on 
the surface of cocatalyst rather than bulk $\mathrm{TiO}_{2}$. Consistent with this interpretation, a control experiment without loaded $\mathrm{Pd}$ cocatalyst cannot generate any $\mathrm{H}_{2} / \mathrm{HD}$ product (Supplementary Fig. 13). Thus, the origin of HD gas is likely from HDO. In order to verify our hypothesis, some compared experiments for the system of $\mathrm{D}_{2} \mathrm{O} / \mathrm{CH}_{3} \mathrm{OH} / \mathrm{TiO}_{2}$ were carried out (Supplementary Fig. 14). The volume ratios selected for $\mathrm{CH}_{3} \mathrm{OH}$ are from 5 to $20 \%$. In these samples, few $\mathrm{HDO}$ and $\mathrm{CH}_{3} \mathrm{OD}$ species would be generated. After the irradiation with $\mathrm{UV} / \mathrm{V}$ is light for $7 \mathrm{~h}$, no $\mathrm{H}_{2} / \mathrm{HD}$ NMR signal is observed. Thus, we can safely infer that the reduction process for $\mathrm{CH}_{3} \mathrm{OH} / \mathrm{CH}_{3} \mathrm{OD}$ to produce $\mathrm{H}_{2} / \mathrm{HD}$ is quite limited within $7 \mathrm{~h}$ in this system. That is to say, the origin of HD gas in System 1 is mainly from HDO. Similarly, in System 2, we prolonged the illumination time to $24 \mathrm{~h}$; only trace amount of $\mathrm{HD}$ gas was found (this might indicate that the concentration of $\mathrm{HDO}$ is much more smaller than $\mathrm{D}_{2} \mathrm{O}$ in this sample). The results provide a compelling evidence that the dominating proton source of $\mathrm{H}_{2}$ gas in the HER of $\mathrm{CH}_{3} \mathrm{OH} / \mathrm{H}_{2} \mathrm{O}$ /catalyst mixture $\left(\mathrm{CH}_{3} \mathrm{OH}\right.$ $\mathrm{Vol} \%<20 \%)$ is $\mathrm{H}_{2} \mathrm{O}$ species, and $\mathrm{H}_{2}$ gas from the photoreforming process of $\mathrm{CH}_{3} \mathrm{OH}$ in the $\mathrm{CH}_{3} \mathrm{OH} / \mathrm{H}_{2} \mathrm{O}$ mixture solution is negligible.

Note that in a mixture of $\mathrm{H}_{2} \mathrm{O}$ and $\mathrm{CD}_{3} \mathrm{OD}$, some $\mathrm{H}_{3} \mathrm{O}^{+}$and $\mathrm{CH}_{3} \mathrm{OH}_{2}^{+}$(as well as $\mathrm{OH}^{-}$and $\mathrm{CH}_{3} \mathrm{O}^{-}$) species may also be generated by autoprotolysis. In this study, the $\mathrm{pH}$ value of the system is 7. The influence of the concentration of $\mathrm{H}_{3} \mathrm{O}^{+} / \mathrm{OH}^{-}$ and $\mathrm{CH}_{3} \mathrm{OH}_{2}^{+} / \mathrm{CH}_{3} \mathrm{O}^{-}$on the photocatalytic reaction is the ongoing study in our laboratory.

To get a better understanding of the role of methanol, a series of ${ }^{13} \mathrm{C}$-labelled methanol $\left({ }^{13} \mathrm{CH}_{3} \mathrm{OH}\right)$ instead of the naturally abundant component was added in the reaction system $\left(\mathrm{D}_{2} \mathrm{O} /{ }^{13} \mathrm{CH}_{3} \mathrm{OH} /\right.$ catalyst). Figure 3 shows the ${ }^{1} \mathrm{H} /{ }^{13} \mathrm{C}$ NMR spectra of methanol intermediates of the reaction system containing $\mathrm{Pd} / \mathrm{TiO}_{2}, \mathrm{D}_{2} \mathrm{O}$ and $\mathrm{CH}_{3} \mathrm{OH}$. In this system, $\mathrm{CH}_{3} \mathrm{OD}$ would be generated because of the fast $\mathrm{H} / \mathrm{D}$ exchange reactions. Interestingly, after irradiating for $40 \mathrm{~h}$, the ${ }^{1} \mathrm{H}$ NMR spectrum shows a well-resolved triplet signal with equal intensities (1:1:1 triplet, $J=1.4 \mathrm{~Hz}$ ) at the right side of the $\mathrm{CH}_{3}$ peak of $\mathrm{CH}_{3} \mathrm{OH}(\mathrm{D})$ (Fig. 3a). While similar triplet signals can also be observed from the ${ }^{13} \mathrm{C}$ NMR spectrum (Fig. 3b). According to the chemical shift and the characteristic $J$ coupling value, we have assigned these two signals to $\mathrm{CH}_{2} \mathrm{D}$ - of $\mathrm{CH}_{2} \mathrm{DOH}(\mathrm{D})$. The possibility of -CHDcan be easily ruled out by the observation in the $1 \mathrm{D}{ }^{13} \mathrm{C}$ DEPT-135 (Distortionless Enhancement by Polarizition Transfer) spectrum where the triplet signals show clear negative intensities (Fig. 3b, inset).

For the formation of $\mathrm{CH}_{2} \mathrm{DOH}(\mathrm{D})$, two processes can be proposed: one is through an addition reaction of $\mathrm{HCHO}$ and $\mathrm{HD}$, while the other is through the reaction of $\bullet \mathrm{CH}_{2} \mathrm{OH}(\mathrm{D})$ with $\mathrm{D}$ radicals $(\bullet \mathrm{D})$. It has been reported that the average adsorption energy of $\mathrm{HCHO}$ is much lower than that of $\mathrm{CH}_{3} \mathrm{OH}$; therefore, it may desorb from the $\mathrm{TiO}_{2}$ surface quickly rather than recombine with an H/D atom ${ }^{19}$. Furthermore, as will be discussed in a further publication, the $\mathrm{HCHO}$ may transform into methanediol species quickly in the aqueous solution, which accelerates the desorption rate of $\mathrm{HCHO}$. It is therefore reasonable to conclude that the $\mathrm{CH}_{2} \mathrm{DOH}(\mathrm{D})$ is likely formed through a coupling reaction of $\bullet \mathrm{CH}_{2} \mathrm{OH}(\mathrm{D})$ and $\bullet \mathrm{D}$, providing an indirect evidence of the existence of $\bullet \mathrm{CH}_{2} \mathrm{OH}(\mathrm{D})$ radicals during the HER. Meanwhile, $\bullet \mathrm{CH}_{2} \mathrm{OH}(\mathrm{D})$ is the inevitable intermediate when $\mathrm{CH}_{3} \mathrm{OH}(\mathrm{D})$ reacts with a hole $\left(\mathrm{h}^{+}\right)$, which gives a definitive evidence that $\mathrm{CH}_{3} \mathrm{OH}$ serves as a sacrificial agent and plays a crucial role in mediating the capture of holes to form $\bullet \mathrm{CH}_{2} \mathrm{OH}$ radicals. To our knowledge, $\bullet \mathrm{CH}_{2} \mathrm{OH}$ species only exists in the liquid (may not be present in the ideal conditions) and is hard to be captured when it is in an isolated state, while it would also rapidly convert to $\mathrm{HCHO}$ (as also confirmed by DFT), thus
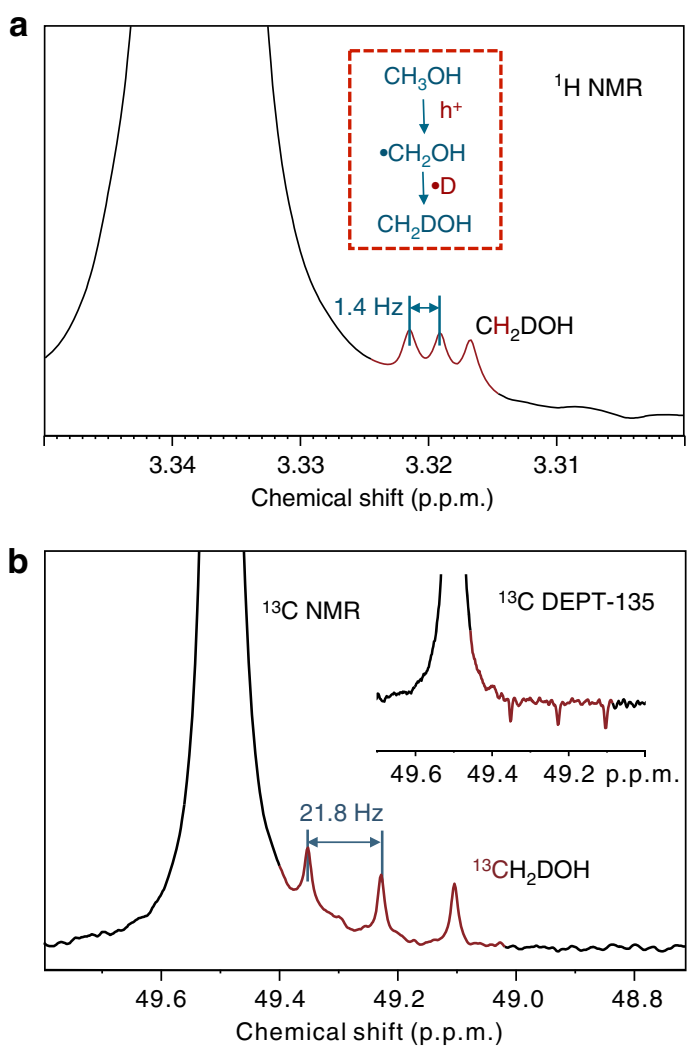

Figure 3 | High resolution NMR spectra of as-prepared samples.

(a) ${ }^{1} \mathrm{H}$ NMR spectrum of the methanol intermediates after the UV/Vis irradiation. The ${ }^{1} \mathrm{H}$ NMR experiment was acquired from samples containing $\mathrm{Pd} / \mathrm{TiO}_{2}(2 \mathrm{mg}), \mathrm{CH}_{3} \mathrm{OH}(20 \mu \mathrm{l})$ and $\mathrm{D}_{2} \mathrm{O}(500 \mu \mathrm{l})$ at $298 \mathrm{~K}$ with a $5 \mathrm{~s}$ recycle delay and 16 scans after the UV/Vis irradiation for $40 \mathrm{~h}$. (b) ${ }^{13} \mathrm{C}$ NMR spectrum of the methanol intermediates after the UV/Vis irradiation. The ${ }^{13} \mathrm{C}$ NMR experiment was acquired from samples containing $\mathrm{Pd} / \mathrm{TiO}_{2}$ $(2 \mathrm{mg}),{ }^{13} \mathrm{CH}_{3} \mathrm{OH}(20 \mu \mathrm{l})$ and $\mathrm{D}_{2} \mathrm{O}(500 \mu \mathrm{l})$ at $298 \mathrm{~K}$ with a $2 \mathrm{~s}$ recycle delay and 32 scans after the UV/Vis irradiation for $40 \mathrm{~h}$. Inset is the DEPT-135 NMR spectrum of the as-prepared samples. The DEPT-135 spectrum was acquired from samples containing $\mathrm{Pd} / \mathrm{TiO}_{2}(2 \mathrm{mg}$ ),

${ }^{13} \mathrm{CH}_{3} \mathrm{OH}(20 \mu \mathrm{l})$ and $\mathrm{D}_{2} \mathrm{O}(500 \mu \mathrm{l})$ at $298 \mathrm{~K}$ with a $1 \mathrm{~s}$ recycle delay and 32 scans after the UV/Vis irradiation for $40 \mathrm{~h}$. In the DEPT-135 spectrum, the negative ${ }^{13} \mathrm{C}$ signals indicate that the signals are from the partially deuterated methyl $\left(-\mathrm{CH}_{2} \mathrm{D}\right)$.

resulting in a lacking experimental evidence and unconfirmed mechanisms for this important process.

DFT studies. For a better understanding of the reaction mechanism, we have also conducted systematic DFT calculations concerning the reactions of $\mathrm{CH}_{3} \mathrm{OH}$ at both ground and excited states on the anatase- $\mathrm{TiO}_{2}$ (101) surface ${ }^{34,35}$. The results are illustrated in Fig. 4a (ground state) and Fig. 4b (excited state). As one can see, at the ground state, the dissociation of methanol through breaking of $\mathrm{O}-\mathrm{H}$ or $\mathrm{C}-\mathrm{H}$ bond is obviously an endothermic process. Therefore, the $\mathrm{CH}_{3} \mathrm{OH}$ may stay intact at the surface under dark conditions. Interestingly, with the help of $\mathrm{h}^{+}$, both $\mathrm{C}-\mathrm{H}$ and $\mathrm{O}-\mathrm{H}$ bond-breaking reactions become exothermic, and the $\mathrm{C}-\mathrm{H}$ dissociation is more favourable both thermodynamically and dynamically compared with the $\mathrm{O}-\mathrm{H}$ dissociation. It indicates that $\mathrm{CH}_{3} \mathrm{OH}$ may prefer to react with $\mathrm{h}^{+}$to form $\bullet \mathrm{CH}_{2} \mathrm{OH}$ species under excited conditions. Then, $\bullet \mathrm{CH}_{2} \mathrm{OH}$ species may react with $\bullet \mathrm{H}(\bullet \mathrm{D})$ back to methanol or further react with $\mathrm{h}^{+}$to $\mathrm{HCHO}$. Both reactions have also been studied in our calculations, and it turns out that, at the ground 

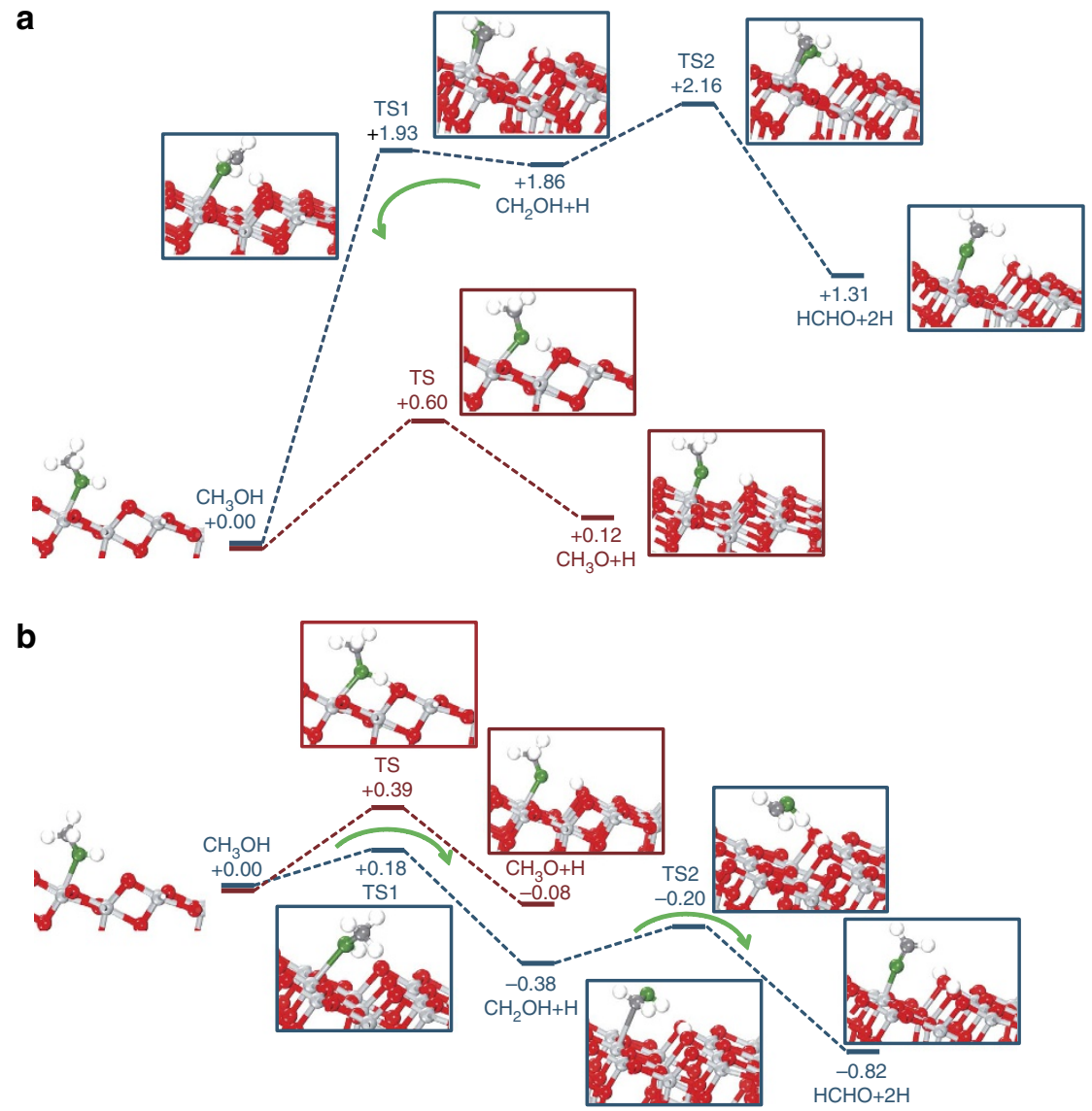

Figure 4 | DFT calculations. (a) DFT of the dissociation of $\mathrm{CH}_{3} \mathrm{OH}$ at the ground state. (b) Photo-oxidation of $\mathrm{CH}_{3} \mathrm{OH}$ begins with $\mathrm{C}-\mathrm{H}$ broken (blue line) and $\mathrm{O}-\mathrm{H}$ broken (red line). The calculated structures are displayed in the profile. The $\mathrm{Ti}$ atoms are in light grey and $\mathrm{O}$ in red, while the $\mathrm{C}$ atoms are in dark grey and $\mathrm{H}$ in white, and $\mathrm{O}$ atom of $\mathrm{CH}_{3} \mathrm{OH}$ are in green. This notation is used throughout this paper.

state, the $\bullet \mathrm{CH}_{2} \mathrm{OH}$ may readily convert back to methanol with the barrier of only $0.07 \mathrm{eV}$ - much lower than the further oxidation to $\mathrm{HCHO}(0.30 \mathrm{eV})$. By contrast, at the excited state, $\mathrm{CH}_{2} \mathrm{OH}$ prefers the further oxidation to $\mathrm{HCHO}$ with a barrier of $0.18 \mathrm{eV}$ rather than returning to methanol, which has a much higher barrier of $0.56 \mathrm{eV}$.

Quantitative operando NMR spectra. Operando NMR can not only provide qualitative insight into the catalytic mechanism but also be fully quantitative deep into the real solid-liquid phases. In our system, $\mathrm{H}_{2}$ gas is a very important product, and its variation tendency may reflect some important microcosmic catalytic processes. Although some other characterization techniques such as gas chromatography (GC) and mass spectrometer (MS) can also be used to measure the gas products, they can only detect the gases that escape from the solution (after the dissolved gas reaches the saturation concentration), whereas in fact quite amount of gas molecules might be already present in the solution with partial dissolution and adsorption at the early stage of the reaction. Furthermore, the microcosmic reaction processes and trends before the dissolved gas reaches the saturation concentration will be missing, and the processes could last for more than $10 \mathrm{~min}$ for the $40 \mathrm{nmol} \mathrm{H}_{2}$ dissolving in $100 \mathrm{ml} \mathrm{H}_{2} \mathrm{O}$ solution. Meanwhile, it is also impossible for GC or MS to probe some intermediates that cannot escape from the reaction solution. In this context, the operando NMR approach is superior to GC or MS in studying the HER.

In our system, assuming that the $\mathrm{H}_{2}$ gas does not reach the saturation state at the early stage of the reaction, the observed $\mathrm{H}_{2}$

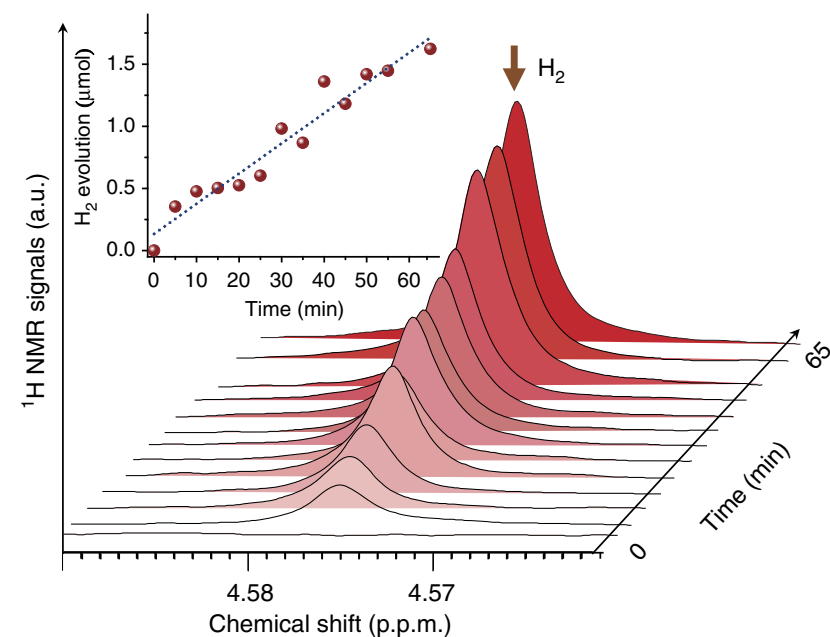

Figure 5 | Quantitative operando ${ }^{\mathbf{H}} \mathbf{H}$ NR spectra. Quantitative timerelated ${ }^{1} \mathrm{H}$ NMR spectra of $\mathrm{Pd} / \mathrm{TiO}_{2}$ at $298 \mathrm{~K}$ in $\mathrm{H}_{2} \mathrm{O} / \mathrm{CD}_{3} \mathrm{OD}$ mixtures under UV/Vis light irradiation. The operando NMR experiments were acquired from samples containing $\mathrm{Pd} / \mathrm{TiO}_{2}(1 \mathrm{mg}), \mathrm{CD}_{3} \mathrm{OD}(300 \mu \mathrm{l}), \mathrm{D}_{2} \mathrm{O}$ ( $1 \%$ DSS as the internal reference) and $\mathrm{H}_{2} \mathrm{O}(300 \mu \mathrm{l})$ at $298 \mathrm{~K}$ with a $5 \mathrm{~s}$ recycle delay and eight scans under the UV/Vis irradiation. The first 1,000 points of the FID was cut off to obtain the final separable $\mathrm{H}_{2}$ signals.

signals in the NMR spectra could reflect the whole $\mathrm{H}_{2}$ gas from HER. $\mathrm{H}_{2}$ gas can be quantified by using the intensity of the $\mathrm{H}_{2}$ signal in the $\mathrm{H}_{2}-\mathrm{D}_{2} \mathrm{O}$ saturation solution (estimate $0.018 \mathrm{ml} \mathrm{H}_{2}$ 
per $1 \mathrm{ml} \mathrm{D}_{2} \mathrm{O}$ ) at the same temperature (Supplementary Figs 15 and 16). Through comparison of the $\mathrm{H}_{2}$ resonance intensities with calibration samples, it is possible to quantify the number of $\mathrm{H}_{2}$ species in absolute terms at the early stage and gain insight into the PT behaviour properties in working state. Figure 5 shows the quantitative operando ${ }^{1} \mathrm{H}$ NMR spectrum of $\mathrm{H}_{2} \mathrm{O} / \mathrm{CD}_{3} \mathrm{OD} /$ catalyst system. For a suitable comparison with the results obtained from the conventional GC detector (Supplementary Fig. 12), the sample was irradiated directly by an Xe light source. The $\mathrm{H}_{2}$ signal intensity increased linearly on continuous illumination. Under this condition, no HD signal can be detected, and this can be because of the few exchanged HDO products compared with $\mathrm{H}_{2} \mathrm{O}$, consistent with the previous results. The quantification result in Fig. 5 shows that the $\mathrm{H}_{2}$ evolution rate at the early stage from the NMR measurement is $\sim 1.560 \mu \mathrm{mol} \mathrm{h}^{-1}$ $\mathrm{mg}^{-1}$. The above result may be far-reaching because it indicates that the widely used methods have the intrinsic shortcoming on the detection of the reaction especially at the early stage. As a consequence, the reaction models derived from the ex situ measurement, especially the models for the reaction kinetics, will deviate from the actual reaction mechanisms. Thus, this operando NMR spectroscopic method provides an approach to guide the design of HER systems, offering better measures deep into the realistic reaction.

\section{Discussion}

By using an operando NMR method, we successfully quantified the generation of $\mathrm{H}_{2} / \mathrm{HD}$ gases and liquid intermediates in pmol resolution without the separation of products, and provided evidence for the PT routes during the HER. On the basis of the photocatalytic system containing anatase- $\mathrm{TiO}_{2}$, methanol and water, we find that the effective protons for HER are mainly from water, and methanol evidently serves as an outstanding electronic sacrificial agent reacting with holes. However, for the sacrifice reforming process of methanol, a small amount of released methyl group protons still occur, which are likely bound to the surface of $\mathrm{TiO}_{2}$, and their migration to cocatalyst to take part in the HER would consume more time and energy. This indicates that complicated synergistic effect between water and methanol exists under practical HER conditions. The picture in Supplementary Fig. 17 illustrates the paramount PT processes together with the reaction mechanism of HER. Carrier generation and recombination occur when an electron transfers from the valence band to conduction band in a semiconductor. Once the photoexcited charges reach the surface of the particle, they can take part in surface redox reactions with adsorbed donor or acceptor molecules ${ }^{34-37}$. In our system, the induced electron transfers from the $\mathrm{TiO}_{2}$ conduction band to the metal particles, and the attached proton would be reduced by an electron to its monoatomic radical species $(\bullet \mathrm{H})$, which is the main predecessor of $\mathrm{H}_{2}$ (Supplementary Fig. 17, (equation 5)). On the other side, the holes would be consumed by $\mathrm{CH}_{3} \mathrm{OH}$, extracting the charges competitively with their recombination and then improving the formation rate of $\mathrm{H}_{2}$. On the oxidative side, two sequential hole consumptions convert the adjacent $\mathrm{CH}_{3} \mathrm{OH}$ species to - $\mathrm{CH}_{2} \mathrm{OH}$ (equation 2) and $\mathrm{HCHO}$ (equation 3), respectively, accompanying with the release of protons. Subsequent spontaneous (dark) coupling reaction between $\bullet \mathrm{CH}_{2} \mathrm{OH}$ and - $\mathrm{H}$ radicals results in $\mathrm{CH}_{3} \mathrm{OH}$ species re-formation (equation 4). On the reductive side, protons would be reduced to hydrogen by the shuttled electrons on the surface of cocatalyst (equation 5). In $\mathrm{H}_{2} \mathrm{O} / \mathrm{CH}_{3} \mathrm{OH} \quad\left(\mathrm{CH}_{3} \mathrm{OH}\right.$ vol $\left.\%<20 \%\right)$ mixtures, $\mathrm{H}_{2} \mathrm{O}$ molecules would provide a vast amount of free protons in solution (equation 1). Although the photocatalytically dissociated protons from $\mathrm{CH}_{3} \mathrm{OH}$ are constrained by the $\mathrm{O}_{\mathrm{BBO}}$ nearby, only a slim chance for those to be reduced to $\mathrm{H}_{2}$ exists. As a consequence, the current NMR spectroscopic studies provide a unique viewing angle for us to understand the predominant PT processes of HER in solution.

The results in this work deepen our understanding of interfacial heterogeneous redox reactions, and the operando NMR method will be applicable extensively with the methodology offering exciting possibilities for the microcosmic mechanism study (pmol resolution) in catalysis, photoelectrocatalysis and electrocatalysis of reactions such as $\mathrm{CO}_{2}$ reduction, waste-water remediation and methanol reforming.

\section{Methods}

Synthesis of catalyst. The $\mathrm{Pd}(1.0 \mathrm{wt} \%) / \mathrm{TiO}_{2}$ photocatalyst powder was prepared by the co-precipitation method. Briefly, appropriate amount of $\mathrm{PdCl}_{2}$ aqueous solution $(1 \mathrm{wt} \%)$ was added into the $\mathrm{TiO}_{2}(100 \mathrm{mg}$, Anatase, Sigma) powder and maintained at $80^{\circ} \mathrm{C}$ for $1 \mathrm{~h}$. After being dried, the products were calcined at $300^{\circ} \mathrm{C}$ for $2 \mathrm{~h}$. Before being characterized and tested, the samples were reduced in $20 \%$ $\mathrm{H}_{2} / \mathrm{Ar}$ at $300^{\circ} \mathrm{C}$ for $1 \mathrm{~h}$.

NMR experiment. All NMR experiments were acquired on $700 \mathrm{MHz}$ Agilent NMR spectrometers at a magnetic field strength of $16.4 \mathrm{~T}$. An Agilent $5 \mathrm{~mm} \mathrm{z}$-axis pulsed field gradient triple-resonance static probe was used in all ${ }^{1} \mathrm{H}$ and ${ }^{13} \mathrm{C}$ NMR experiments. All ${ }^{1} \mathrm{H}$ NMR measurements were carried out at $298 \mathrm{~K}$ with a spectral width of 20 p.p.m., pulse width of $4 \mu$ s $\left(45^{\circ}\right)$, a recycle delay of $5 \mathrm{~s}$ and 8,16 or 32 scans. To suppress the water signal, the first 1,000 points of the free induction decay (FID) were cut off before FT. ${ }^{13} \mathrm{C}$ NMR was carried out at $298 \mathrm{~K}$ with a spectral width of 253 p.p.m., pulse width of $7.3 \mu$ s $\left(45^{\circ}\right)$, a recycle delay of $2 \mathrm{~s}$ and 32 scans. All experiments had DSS as the internal reference. To enhance the NMR signals, the examples could also be directly

irradiated by an Xe light source during the irradiation accumulation process.

Operando ${ }^{1} H$ NMR studies. A $300-\mathrm{W}$ Xe lamp was used as the light source. The light source is outside the magnet. The light source beam was directed through a focusing lens assembly to converge on the entrance face of a homemade optical fibre bundle (seven quartz fibres, diameter $3 \mathrm{~mm}$ ). The cap of the tube was specially designed to allow the input of the light and the $\mathrm{H}_{2}$ gas. Note that the fibre may lead to an attenuation of the light intensity and a lower reaction rate (see Fig. 5 and Supplementary Fig. 18). In order to simulate the HER process similar to the conventional GC, the samples might be irradiated directly by an Xe light source.

Calculation details. All the calculations were carried out using the Vienna $a b$ initio simulation package ${ }^{38,39}$, and the exchange-correlation term was described by the Perdew, Burke and Ernzerhof version within the generalized gradient approximation ${ }^{40}$. The project-augmented wave ${ }^{41,42}$ method was used to represent the core-valence electron interaction. The titanium $3 s, 3 p, 3 d, 4 s$ and the carbon and oxygen $2 s, 2 p$ electrons were treated as valence electrons and an energy cutoff of $400 \mathrm{eV}$ for the basis-set expansion was used.

The anatase- $\mathrm{TiO}_{2}$ (101) surface was modelled by a five trilayer slab with only the centre layer fixed, and other atoms were allowed to relax until atomic forces reached below $0.05 \mathrm{eV}^{-1}$. As suggested by Luo and co-workers ${ }^{43}$, the hole was introduced by using the triplet state to mimic the singlet excited state ${ }^{43-47}$. A $3 \times 1$ surface cell and a $>15 \AA$ vacuum gap was used. Different $\mathrm{k}$-point meshes were tested, and it was found the k-point sampling restricted to the $\Gamma$ point only can already provide reliable results regarding adsorption energies.

The transition states in reactions were located with a constrained optimization scheme $^{48}$, and were verified when (i) all forces on atoms vanish and (ii) the when total energy is maximum along the reaction coordinate but minimum with respect to the rest of the degrees of freedom.

Data availability. All relevant data are available from the authors.

\section{References}

1. Han, Z., Qiu, F., Eisenberg, R., Holland, P. L. \& Krauss, T. D. Robust photogeneration of $\mathrm{H}_{2}$ in water using semiconductor nanocrystals and a nickel catalyst. Science 338, 1321-1324 (2012).

2. Liu, J. et al. Metal-free efficient photocatalyst for stable visible water splitting via a two-electron pathway. Science 347, 970-974 (2015).

3. Hundt, P. M., Jiang, B., Reijzen, M. E., Guo, H. \& Beck, R. D. Vibrationally promoted dissociation of water on Ni (111). Science 334, 504-507 (2014).

4. Nielsen, M. et al. Low-temperature aqueous-phase methanol dehydrogenation to hydrogen and carbon dioxide. Nature 495, 85-90 (2013).

5. McLaren, A. D. The beckmann rearrangement of aliphatic ketoximes. Science 103, 503 (1946).

6. Corma, A. \& García, H. Lewis acids: from conventional homogeneous to green homogeneous and heterogeneous catalysis. Chem. Rev. 103, 4307-4365 (2003). 
7. Clarke, H. T., Gillespie, H. B. \& Weisshaus, S. Z. The action of formaldehyde on amines and amino acids. J. Am. Chem. Soc. 446, 4571-4587 (1933).

8. Albrecht, $Ł$. et al. Asymmetric organocatalytic formal $[2+2]$-cycloadditions via bifunctional $\mathrm{H}$-bond directing dienamine catalysis. J. Am. Chem. Soc. 134, 2543-2546 (2012)

9. Heyduk, A. F. \& Nocera, D. G. Hydrogen produced from hydrohalic acid solutions by a two-electron mixed-valence photocatalyst. Science 293, 1639-1641 (2001).

10. Chen, X., Shen, S., Guo, L. \& Mao, S. S. Semiconductor-based photocatalytic hydrogen generation. Chem. Rev. 110, 6503-6570 (2010).

11. Onishi, H. \& Iwasawa, Y. Dynamic visualization of a metal-oxide-surface/gasphase reaction: time-resolved observation by scanning tunneling microscopy at 800 K. Phys. Rev. Lett. 76, 791-794 (1996).

12. Scheiber, P., Riss, A., Schmid, M., Varga, P. \& Diebold, U. Observation and destruction of an elusive adsorbate with STM: $\mathrm{O}_{2} / \mathrm{TiO}_{2}$ (110). Phys. Rev. Lett. 105, 216101 (2010)

13. Zhang, Z., Bondarchuk, O., White, J. M., Kay, B. D. \& Dohnálek, Z. Imaging adsorbate O-H bond cleavage: methanol on $\mathrm{TiO}_{2}(110)$. J. Am. Chem. Soc. 128, 4198-4199 (2006)

14. Li, B. Ultrafast interfacial proton-coupled electron transfer. Science 311, 1436-1440 (2006)

15. Xu, C. et al. Molecular hydrogen formation from photocatalysis of methanol on anatase- $\mathrm{TiO}_{2}$ (101). J. Am. Chem. Soc. 136, 602-605 (2014)

16. Xu, C. et al. Molecular hydrogen formation from photocatalysis of methanol on $\mathrm{TiO}_{2}$ (110). J. Am. Chem. Soc. 135, 19039-19045 (2013).

17. Guo, Q. et al. Stepwies photocatalytic dissociation of methanol and water on $\mathrm{TiO}_{2}$ (110). J. Am. Chem. Soc. 134, 13366-13373 (2012).

18. Zhang, M., Respinis, M. \& Frei, H. Time-resolved observations of water oxidation intermediates on a cobalt oxide nanoparticle catalyst. Nat. Chem. 6, 362-367 (2014)

19. Highfield, J. G., Chen, M. H., Nguyen, P. T. \& Chen, Z. Mechanistic investigations of photo-driven processes over $\mathrm{TiO}_{2}$ by in-situ DRIFTS-MS: part 1. Platinization and methanol reforming. Energ. Environ. Sci. 2, 991-1002 (2009).

20. Chen, T. et al. Mechanistic studies of photocatalytic reaction of methanol for hydrogen production on $\mathrm{Pt} / \mathrm{TiO}_{2}$ by in situ fourier transform IR and time-resolved IR spectroscopy. J. Phys. Chem. C 111, 8005-8014 (2007).

21. Blanc, F., Leskes, M. \& Grey, C. P. In situ solid-state NMR spectroscopy of electrochemical cells: batteries, supercapacitors, and fuel cells. Acc. Chem. Res. 46, 1952-1963 (2013).

22. Cattaneo, A. S. et al. Operando electrochemical NMR microscopy of polymer fuel cells. Energy Environ. Sci. 8, 2383-2388 (2015).

23. Chan, K. W. H. \& Wieckowski, A. Probing adsorbates on Pt electrode surfaces by the use of ${ }^{13} \mathrm{C}$ spin-echo NMR. Studies of CO generated from methanol electrosorption. J. Electrochem. Soc. 137, 367-368 (1990).

24. Tong, Y. Y., Wieckowski, A. \& Oldfield, E. NMR of electrocatalysts. J. Phys. Chem. B 106, 2434-2446 (2002).

25. Sánchez, V. M., Cojulun, J. A. \& Scherlis, D. A. Dissociation free energy profiles for water and methanol on $\mathrm{TiO}_{2}$ surfaces. J. Phys. Chem. C 114, 11522-11526 (2010).

26. Setvin, M. et al. Reaction of $\mathrm{O}_{2}$ with subsurface oxygen vacancies on $\mathrm{TiO}_{2}$ anatase (101). Science 341, 988-991 (2013).

27. Huang, J., Jiang, Y., Vegten, N., Hunger, M. \& Baiker, A. Tuning the support acidity of flame-made $\mathrm{Pd} / \mathrm{SiO}_{2}-\mathrm{Al}_{2} \mathrm{O}_{3}$ catalysts for chemoselective hydrogenation. J. Catal. 281, 352-360 (2011).

28. Kolmer, A. et al. The influence of electronic modifications on rotational barriers of bis-NHC-complexes as observed by dynamic NMR spectroscopy. Magn. Reson. Chem. 51, 695-700 (2013).

29. Suleimanov, N. M. et al. In situ muSR and NMR investigation of methanol dissociation on carbon-supported nanoscaled Pt-Ru catalyst. J. Solid State Electrochem. 17, 2115-2121 (2013).

30. Schrauben, J. N. et al. Titanium and zinc oxide nanoparticles are protoncoupled electron transfer agents. Science 336, 1298-1301 (2012).

31. Krishtalik, L. I. Kinetic isotope effect in the hydrogen evolution reaction. Electrochim. Acta 46, 2949-2960 (2001).

32. Urey, H. C., Brickwedde, F. G. \& Murphy, G. M. A hydrogen isotope of mass 2 and its concentration. Phy. Rev. 40, 1-15 (1932).

33. Fenby, D. V. \& Chand, A. Thermodynamic study of deuterium exchange in water + methanol systems. J. Chem. Soc. Faraday Trans. 74, 1768-1775 (1978).

34. Lin, K., Zhou, X., Luo, Y. \& Liu, S. The microscopic structure of liquid methanol from raman spectroscopy. J. Phys. Chem. B 114, 3567-3573 (2010).

35. Valero, M. C., Raybaud, P. \& Sautet, P. Nucleation of $\operatorname{Pd}_{n}(n=1-5)$ clusters and wetting of Pd particles on $\gamma-\mathrm{Al}_{2} \mathrm{O}_{3}$ surfaces: a density functional theory study. Phys. Rev. B 75, 045427 (2007).
36. Gerritzen, D. \& Limbach, H. H. Kinetic and equilibrium isotope effects of proton exchange and autoprotolysis of pure methanol studies by dynamic NMR spectroscopy. Ber. Bunsenges. Phys. Chem. 85, 527-535 (1981).

37. Galińska, A. \& Walendziewski, J. Photocatalytic water splitting ove Pt- $\mathrm{TiO}_{2}$ in the presence of sacrificial reagents. Energy and Fuels 19, 1143-1147 (2005).

38. Kresse, G. \& Furthmüller, J. Efficiency of ab-initio total energy calculations for metals and semiconductors using a plane-wave basis set. Comput. Mater. Sci. 6, 15-50 (1996)

39. Kresse, G. \& Furthmüller, J. Efficient iterative schemes for ab initio totalenergy calculations using a plane-wave basis set. Phys. Rev. B 54, 11169-11186 (1996).

40. Perdew, J. P., Burke, K. \& Ernzerhof, M. Generalized gradient approximation made simple. Phys. Rev. Lett. 77, 3865-3868 (1996).

41. Kresse, G. \& Joubert, D. From ultrasoft pseudopotentials to the projector augmented-wave method. Phys. Rev. B 56, 1758-1775 (1999)

42. Blöchl, P. E. Projector augmented-wave method. Phys. Rev. B 50, 17953-17979 (1994).

43. Ji, Y., Wang, B. \& Luo, Y. A comparative theoretical study of proton-coupled hole transfer for $\mathrm{H}_{2} \mathrm{O}$ and small organic molecules $\left(\mathrm{CH}_{3} \mathrm{OH}, \mathrm{HCOOH}, \mathrm{H}_{2} \mathrm{CO}\right)$ on the anatase $\mathrm{TiO}_{2}$ (101) Surface. J. Phys. Chem. C 118, 21457-21462 (2014)

44. Ji, Y., Wang, B. \& Luo, Y. Location of trapped hole on rutile- $\mathrm{TiO}_{2}$ (110) surface and its role in water oxidation. J. Phys. Chem. C 116, 7863-7866 (2012).

45. Di, V. C. \& Fittipaldi, D. Hole scavenging by organic adsorbates on the $\mathrm{TiO}_{2}$ surface: a DFT model study. J. Phys. Chem. Lett. 4, 1901-1906 (2013).

46. Ji, Y., Wang, B. \& Luo, Y. First principles study of $\mathrm{O}_{2}$ adsorption on reduced rutile $\mathrm{TiO}_{2}$ (110) surface under UV illumination and its role on CO oxidation. J. Phys. Chem. C 117, 956-961 (2013).

47. Jedidi, A., Markovits, A., Minot, C., Bouzriba, S. \& Abderraba, M. Modeling localized photoinduced electrons in rutile- $\mathrm{TiO}_{2}$ using periodic DFT $+\mathrm{U}$ methodology. Langmuir 26, 16232-16238 (2010).

48. Alavi, A., Hu, P., Deutsch, T., Silvestrelli, P. L. \& Hutter, J. CO oxidation on Pt (111): an ab initio density functional theory study. Phys. Rev. Lett. 80, 3650-3653 (1998).

\section{Acknowledgements}

This work was financially supported by the National Natural Science Foundation of China $(21373083,21421004,21322307$ and 21574043), the Fundamental Research Funds for the Central Universities (WD1313009 and WD1514303), SRF for ROCS, SEM, SRFDP, Program of Shanghai Subject Chief Scientist (15XD1501300), National High-tech R\&D Program of China (863 Program; 2014AA123400, 2014AA123401).

\section{Author contributions}

H.G.Y. conceived the project and contributed to the design of the experiments and analysis of the data. X.L.W. performed the catalyst preparation, characterizations and wrote the paper. Y.-F.Y., Y.S., W.Q.F., D.W. and W.L. conducted the NMR examination and contributed to writing the NMR section. X.-Q.G. and Y.-Y.Y. conducted DFT calculations and wrote part of the paper (calculations). All the authors discussed the results and commented on the manuscript.

\section{Additional information}

Supplementary Information accompanies this paper at http://www.nature.com/ naturecommunications

Competing financial interests: The authors declare no competing financial interests

Reprints and permission information is available online at http://npg.nature.com/ reprintsandpermissions/

How to cite this article: Wang, X. L. et al. Operando NMR spectroscopic analysis of proton transfer in heterogeneous photocatalytic reactions. Nat. Commun. 7:11918 doi: $10.1038 /$ ncomms11918 (2016).

This work is licensed under a Creative Commons Attribution 4.0 International License. The images or other third party material in this article are included in the article's Creative Commons license, unless indicated otherwise in the credit line; if the material is not included under the Creative Commons license, users will need to obtain permission from the license holder to reproduce the material. To view a copy of this license, visit http://creativecommons.org/licenses/by/4.0/ 